\title{
A hybrid of Borda-TOPSIS for risk analysis of Islamic state network development in southeast Asia
}

\author{
Mohd Zaini Salleha, Azrul Azlan Abd Rahmana ${ }^{\text {a }}$, Rogis Baker ${ }^{\mathrm{a}}$, A. Octavian ${ }^{\mathrm{a}}$, Joni Widjayanto ${ }^{\mathrm{b}}$, I \\ Nengah Putra ${ }^{b^{*}}$ and Pujo Widodo
}

\begin{tabular}{l}
${ }^{a}$ National Defence University of Mal \\
${ }^{b}$ The Indonesia Defense Universit \\
\hline C H R O N I C L E \\
\hline Article history: \\
Received October 27,2020 \\
Received in revised format: \\
October 29, 2020 \\
Accepted November 112020 \\
Available online \\
November 11,2020 \\
\hline Keywords: \\
Risk Analysis \\
Islamic State (IS) \\
Borda \\
TOPSIS \\
Southeast Asia
\end{tabular}

\section{Introduction}

BORDA is a method used to rank preferential decisions. The BORDA method is used in group decision making to rank candidates based on the choices of each decision-maker. Borda is a method used in group decision making for single or multiple winner elections, where voters rank the candidates based on preference (Srdjevic et al., 2017). TOPSIS is a multicriteria decision-making method or choice which is based on the iodea of choosing an alternative that has the smallest distance from the positive ideal solution and the largest distance from the negative ideal solution in terms of a geometric point of view using the Euclidean distance (Norouzi \& Namin, 2019). This method is widely used for decision making that has many multicriteria or criteria (Wang \& Duan, 2019). Both methods are part of the multicriteria decision making in the MCDM method (Alencar et al., 2010).

Multi-Criteria Decision Making is a set of methods that deal with evaluating a series of alternatives that are many, often contradictory, and with various criteria (Gavade, 2014). In a decision-making environment related to risk, there are four
In a decision-making environment related to risk, there are four basic circumstances, namely certainty, risk, uncertainty and conflict. The dynamics of the strategic environment in Southeast Asia cannot be separated from the movement of the development of the Islamic State (IS). The terror threat in Southeast Asia is currently divided into different generations of terror, namely the threat of the Al-Qaeda terror network and the threat of the ISIS terror network. This study aims to analyze and identify the risk value of the development of the Islamic State network in Southeast Asia using the Borda and TOPSIS methods. The Borda method is used to give weight score. This research is limited to the Southeast Asia region with 4 (four) major countries, namely Indonesia, Malaysia, Thailand, and the Philippines. This research is expected to contribute to control the development of Islamic state networks in the Southeast Asian region. Based on the results of the overall risk analysis, it was found that the Philippines has the highest risk factor value for Islamic State (IS) with a value of 0.550 at level 4 in the High category. Indonesia maintains a risk factor value of 0.307 . Thailand has a risk factor value of 0.427 . Indonesia and Thailand are at level 3 with the Medium category. Meanwhile, Malaysia has a risk factor value of 0.203 at level 2 in the Low category. 
basic circumstances, namely certainty, risk, uncertainty and conflict. One of the functions of MCDM is as a method of providing a risk analysis (Brito \& Evers, 2016).

The dynamics of the strategic environment in Southeast Asia cannot be separated from the movement of the development of the Islamic State (IS). Currently, almost all countries face cases of the threat of terrorism, both separatism in the Islamic region and the anarchic activities of the international terror network. The terror threat in Southeast Asia is currently divided into three generations of terror, namely the threat of the Al-Qaeda terror network, the second is the threat of the ISIS terror network (Samuel, 2016).

Based on these conditions, this study aims to analyze and identify the risk value of the development of the Islamic State network in Southeast Asia using the Borda and TOPSIS methods approach. The Borda method is used to give weight to the criteria related to risk analysis. The TOPSIS method is used to provide a criteria-based risk score.

This research is limited to the Southeast Asia region with 4 (four) major countries, namely Indonesia, Malaysia, Thailand, and the Philippines. This research is expected to contribute to controlling the development of Islamic state networks in the Southeast Asian region.

There are several previous studies in support of this text, likely Data Analysis Method Of Terrorist Attacks Based On AHPDBSCAN Method (Wang et al., 2019). Risk Evaluation Of Terrorist Attacks Against Important Chemical Industries In Urban Areas (Yang, 2019). A Decision Framework For Managing The Risk Of Terrorist Threats At Rail Stations Interconnected With Airports (Kaewunruen et al., 2018). The Risk Assessment Of Terrorist Attacks Coupled With MultiSource Factors (Zhang, et al., 2018). Risk Assessment And The Prevention Of Radicalization From Nonviolence Into Terrorism (Sarma, 2017). TOPSIS-Borda method for Determination System Education Program (Sari et al., 2020). Risk Level Evaluation on Construction Project Lifecycle Using Fuzzy Comprehensive Evaluation and TOPSIS (Gebrehiwet \& Luo, 2019). Risk Management and Control of Dams Based on Integrating TOPSIS and RAM-D Techniques (Case Study: Paveh Rood Dam, Iran) (Sadeh \& Rezaian, 2017).

This research consists of several sections. Section 2 discusses MCDM theory, Borda Method, TOPSIS method, Risk Analysis, Islamic state, research subjects and objects, research methods and stages. Section 3 describes the results and discussion of the risk analysis of the development of the Islamic State in Southeast Asia. Section 4 describes the conclusions of the study.

\section{Materials and methods}

\subsection{Theory of Multi-Criteria Decision Making (MCDM)}

Multi-Criteria Decision Making (MCDM) is a decision-making method to determine the best alternative from some alternatives based on certain criteria (Chen et al., 2016). Criteria are usually in the form of measures, rules, or standards used in decision making. Multi-Criteria Decision Making (MCDM) is one of the most widely used methods in the area of decision making (Dadras et al., 2014).

The objective of MCDM is to select the best alternative from several mutually exclusive alternatives based on general performance in various criteria (or attributes) determined by the decision-maker. MCDM has two categories, namely Multiple Objective Decision Making (MODM) and Multiple Attribute Decision Making (MADM). There are four steps of decision making in MCDM which include: 1) Problem identification; 2) Setting preferences; 3) Evaluating alternatives; 4) Determine the best alternative (Suharyo, et al., 2017).

There are several common features used in MCDM, namely (Wang et al., 2018):

1. Alternatives are objects that are different and have the same opportunity to be chosen by decision-makers.

2. Attributes, attributes are often referred to as decision criteria.

3. The conflict between criteria, several criteria usually have conflicts with one another. For example, the profit criteria will conflict with the cost criteria.

4. Decision weight, decision weight shows the relative importance of each criterion, $=(1,2,3, \ldots$,$) .$

5. The decision matrix, a decision matrix measuring $x$, contains elements that represent the rating of the alternatives; $=1,2,3, \ldots$, toward the criteria $;=1,2,3, \ldots$, .

\subsubsection{Borda Method}

The Borda method was invented by Jean-Charles de Borda, in the 18th century. The Borda method is a method used in ranking preferential decisions. The Borda method is used in group decision making to rank candidates based on the choices of each decision-maker (Sari et al., 2020). The principle of the Borda method is to make alternative voting by giving weight to each alternative rank. Alternatives that have the highest ranking are given the highest value and so onwards are given a 
lower score for the rank below until the lowest rank is given a value of 0 or 1 . Based on the calculation of the value of the Borda function from the alternative options, the option with the highest value is the choice most preferred by decisionmakers (Srdjevic et al., 2017). The Borda method is a method used to assign ratings to preferential voting. The preferred alternative with the top-ranking position is scored higher than the candidate in the next ranked position in a pairwise comparison. The case resolution stage using the Borda Method can be explained as follows (Merlin, 2020):

1. Determination of the ranking value in an alternative sequence with the top order is given points $\mathrm{m}$ where $\mathrm{m}$ is the total number of choices or alternatives.

2. The point $\mathrm{m}$ is used as the multiplier of the votes earned at the position concerned.

\subsubsection{TOPSIS method}

TOPSIS (Technique For Others Reference by Similarity to Ideal Solution) is one of the multicriteria decision-making methods introduced by Yoon and Hwang (1981). This method uses the principle that the chosen alternative must have the closest distance from the positive ideal solution and the furthest from the negative ideal solution from a geometric point of view (Wan, et al., 2014). Determination of the relative proximity of an alternative with the optimal solution is done by calculating the Euclidean distance. The TOPSIS method considers the distance to the positive ideal solution and the negative ideal solution by taking the relative proximity value to the positive ideal solution (Farmadi, et al., 2015).

The following are the steps for the TOPSIS algorithm in making conclusions (Rađenović \& Veselinović, 2017):

a. Defining problems to be solved using the TOPSIS method.

b. Make a decision matrix according to the problem to be solved, then normalize the matrix with equations.

$$
r_{i j}=\frac{x_{i j}}{\sqrt{\sum_{i=1}^{m} x_{i j}^{2}}}
$$

where rij is the matrix of normalization results from the basic matrix of the problem, with $\mathrm{i}=1,2,3, \ldots . \mathrm{m}$, and $\mathrm{j}=$ $1,2,3 \ldots \mathrm{n}$. Meanwhile, $\mathrm{xij}$ is the basic matrix to be normalized. For each $\mathrm{j}$ denotes the rows of the matrix, and for each $\mathrm{j}$ denotes the columns of each matrix.

c. Perform the normalization of the rij matrix using the weight rating so that the normalized weight rating matrix is obtained, the equation used is as follows

$$
y_{i j}=w_{i} \times r_{i j}
$$

where yij is the weighted rating matrix, wi is the weighted rating to $\mathrm{i}$, and rij is the matrix of normalization results in step two. For $\mathrm{i}=1,2, \ldots, \mathrm{m}$, and $\mathrm{j}=1,2, . ., \mathrm{n}$. In this case, the rating weight must be determined based on the number of decision variables being resolved.

d. $\quad$ Determine the positive ideal solution $(\mathrm{A}+)$ and the ideal negative solution $(\mathrm{A}-)$ based on the weighted rating matrix value in step 3 . The following equation is used to find the ideal positive solution value $A+=(y 1+$, $y 2+, \ldots, y n+)$ and to find the ideal negative solution value the following equation is used $A-=(y 1-, y 2-, \ldots$, $\left.y n^{-}\right)$under the condition :

$$
\begin{aligned}
& y_{i}^{+}=\left\{\begin{array}{l}
\max y_{i j}: \text { if } i \text { is the profit attribute } \\
\min y_{i j}: \text { if } j \text { is cost attribute }
\end{array}\right. \\
& y_{i}^{-}=\left\{\begin{array}{l}
\max y_{i j}: \text { if } i \text { is cost attribute } \\
\min y_{i j: \text { if } j \text { is the profit attribute }}
\end{array}\right.
\end{aligned}
$$

e. Determine the distance between the weighted value of each alternative to the positive ideal solution and the negative ideal solution To determine the distance between the weighted value of each alternative to the positive ideal solution, the following equation is used :

$$
D_{i}^{+}=\sqrt{\sum_{i=1}^{n}\left(y_{i}^{+}-y_{i j}\right)^{2}}
$$


While to calculate the distance between the weighted value of each alternative to the negative ideal solution, the following equation is used:

$$
D_{i}^{-}=\sqrt{\sum_{i=1}^{n}\left(y_{i j}-y_{i}^{-}\right)^{2}}
$$

f. The final step is to calculate the preference value for each alternative using equations:

$$
V_{i}=\frac{D_{I}^{-}}{D_{I}^{-}+D_{I}^{+}}
$$

\section{Risk Analysis}

Risk analysis is a systematic process to determine how often an event and the impact of a risk may occur and how big the consequences of these events. The purpose of risk analysis is to understand the risks that are important to be actively managed and provide data to help prioritize risk treatment (Fuentes-Bargue et al., 2017). Risk analysis can also be interpreted as a process to understand the characteristics of risk (probability and impact) which can be done qualitatively or quantitatively to determine the level of risk or the significance of each risk. The output of the risk analysis is the risk profile (Pavlićević, 2017). In risk analysis, the role of organizational leadership is very necessary so that it can manage and control risk based on how much or what level of risk is acceptable. The acceptable level of risk is the risk tolerance limit by considering the aspects of costs and benefits. Risk analysis will depend on risk information and available data. The analytical method used can be qualitative, semi-quantitative, or quantitative, even a combination of the three depending on the situation and conditions (Zawadzki et al., 2017).

Risk analysis is part of risk management, which consists of the following steps: 1) Identification of possible external and internal negative conditions, events, or situations; 2) Determination of the causal relationship between the probability of the event, its scale, and the likelihood of its impact; 3) Evaluation of various impacts under different assumptions and probabilities; 4) Application of qualitative and quantitative techniques to reduce uncertainty about impacts and costs, liabilities or losses (Ganin et al., 2017). This risk analysis can be written with equations (Liua et al., 2012):

$$
\text { Risk }=\text { Threat } \times \text { Vurnerability }
$$

The purpose of the statement from the formula above is that the threat will exploit a vulnerability so that it can cause an impact on the system, thus making it a risk to the organization (Ezell et al., 2010).

Table 1

Analysis of Scale and Level of Risk (Hosseinnia et al., 2018)

\begin{tabular}{ccc}
\hline Probability Value & Category & Risk Description \\
\hline $0.81-1.0$ & Very High & Death, Inpatient \\
$0.61-0.8$ & High & Severe Injury, Inpatient \\
$0.41-0.6$ & Medium & Medium Medical Care \\
$0.21-0.4$ & Low & Minor injury \\
$0-0.2$ & Very Low & Unscathed \\
\hline
\end{tabular}

\begin{tabular}{|c|c|c|c|c|c|c|}
\hline & \multirow{2}{*}{ Risk Matrix } & \multicolumn{5}{|c|}{ Vulnerability } \\
\hline & & $0-0.2$ & 0.21-0.4 & 0.41-0.6 & $0.61-0.8$ & 0.81-1 \\
\hline \multirow{5}{*}{ 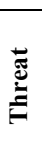 } & $0-0.2$ & Level 1 & Level 1 & Level 2 & Level 2 & Level 3 \\
\hline & $0.21-0.4$ & Level 1 & Level 2 & Level 2 & Level 3 & Level 3 \\
\hline & $0.41-0.6$ & Level 2 & Level 2 & Level 3 & Level 3 & Level 4 \\
\hline & $0.61-0.8$ & Level 2 & Level 3 & Level 3 & Level 4 & Level 4 \\
\hline & 0.81-1 & Level 3 & Level 3 & Level 4 & Level 4 & Level 5 \\
\hline
\end{tabular}

Table 2

Risk Matrix Level (Chien et al., 2019)

Table 3

Risk Level Matrix Value (Chien et al., 2019)

\begin{tabular}{cccccc}
\hline Matrix Value & $\mathbf{0 - 0 . 2}$ & $\mathbf{0 . 2 1 - 0 . 4}$ & $\mathbf{0 . 4 1 - 0 . 6}$ & $\mathbf{0 . 6 1 - 0 . 8}$ & $0-0.16$ \\
\hline $\mathbf{0 - 0 . 2}$ & $0-0.04$ & $0-0.08$ & $0-0.12$ & $0.81-1$ & 0.2 \\
$\mathbf{0 . 2 1 - 0 . 4}$ & $0-0.08$ & $0.04-0.16$ & $0.09-0.24$ & $0.13-0.32$ \\
$\mathbf{0 . 4 1 - 0 . 6}$ & $0-0.12$ & $0.09-0.24$ & $0.17-0.36$ & $0.25-0.48$ & $0.33-0.6$ \\
$\mathbf{0 . 6 1 - 0 . 8}$ & $0-0.16$ & $0.13-0.32$ & $0.25-0.48$ & $0.37-0.64$ & $0.49-0.8$ \\
\hline
\end{tabular}




\section{Islamic State Network}

The dynamic development of the strategic environment brings changes to the complexity of threats that have implications for national defense. The threat of terrorism and radicalism needs serious attention. Because it is cross-country. So it requires collective handling and joint action in dealing with it. With collaboration between countries. The ISIS force based in the Southern Philippines has been used as a terrorist base and has helped trigger terrorist acts in Southeast Asia. The group plans to build a network by combining the Islamic State Philippines, Islamic State Malaysia, and Islamic State Indonesia under the leadership of Mahmud Ahmad. which is part of the Central ISIS structure under the leadership of Iraq-based Abu Bakr Al-Baghdadi (Samuel, 2016). ISIS is a group that represents a new wave of global jihadism previously led by the alQaeda group. ISIS was once affiliated with al-Qaeda for reasons of shared interests. At that time the ISIS group was still called al-Qaeda in Iraq (AQI) with the central division of tasks for Al-Qaeda focusing on far enemies, such as the United States Israel, and other global actors, while AQI focused more on near enemies, namely the Iraqi and Syrian regimes which then spread to the country (Hashim, 2015). Arab countries around it. In 2006 ISIS, which was still called Majelis Shura alMujahidi (MSM), decided to leave al-Qaeda and form a new group. After ISIS unaffiliated with al-Qaeda, the then ISIS leader Abu Bakr al-Bagdadi declared himself the new caliph, namely the supreme leader of Muslims in the world. ISIS also openly challenges al-Qaeda by showing its ambition regarding its group that will become a country that is de facto a major player in the world with the ideology of Salafi jihadism. Then ISIS began targeting far enemies, namely Western countries such as the United States and Europe, it's just that ISIS chose not to attack the territorial areas of far enemy countries but ISIS chose to attack strategic target areas of the West such as Baghdad, Riyadh, and Damascus (Nainggolan, 2017).

\section{Methods and Stages}

In this study, data collection was carried out using questionnaires, interviews, and observations of the instruments prepared. Previously, the instruments were prepared based on the initial criteria of each risk (Threat, Vulnerability).

Table 4

Terrorism Risk Analysis Criteria and Sub Criteria

\begin{tabular}{|c|c|c|c|}
\hline Criteria & Sub Criteria & Code & Reference \\
\hline \multirow{8}{*}{$\begin{array}{c}\text { Threat } \\
(\mathrm{T})\end{array}$} & Existence & $\mathrm{T} 1$ & \multirow{8}{*}{$\begin{array}{l}\text { (Hosseinnia et al., 2018) } \\
\text { (Woo, 2009) } \\
\text { (Zierhoffer, 2014) } \\
\text { (Logan \& Lloyd, 2019) } \\
\text { (Liua et al., 2012) } \\
\text { (Ezell et al., 2010) } \\
\text { (Ganin et al., 2017) }\end{array}$} \\
\hline & Enemy Terror Ability & $\mathrm{T} 2$ & \\
\hline & Historical & $\mathrm{T} 3$ & \\
\hline & Intensity & $\mathrm{T} 4$ & \\
\hline & Type of planning activities & T5 & \\
\hline & Strategic target & T6 & \\
\hline & Total Population & $\mathrm{T} 7$ & \\
\hline & Environmental Safety & $\mathrm{T} 8$ & \\
\hline \multirow{5}{*}{ Vulnerability (V) } & Location & V1 & \multirow{5}{*}{$\begin{array}{l}\text { (Kaewunruen et al., 2018) } \\
\text { (Dumbravă \& Iacob, 2013) } \\
\text { (Hosseinnia et al., 2018) } \\
\text { (Chien et al., 2019) } \\
\text { (Liua et al., 2012) }\end{array}$} \\
\hline & Accessibility & $\mathrm{V} 2$ & \\
\hline & Adequacy of Security & V3 & \\
\hline & Availability & V4 & \\
\hline & Insecurity & V5 & \\
\hline
\end{tabular}

Table 5

Terrorism Risk Analysis Level Value (Hosseinnia et al., 2018; Liua et al., 2012; Cioaca et al., 2016)

\begin{tabular}{ccc}
\hline Score Likert & Threat & Risk Analysis Level \\
\cline { 2 - 3 } & Very High & Vurnerabiliy \\
\hline 5 & High & Very High \\
4 & Medium & High \\
3 & Low & Medium \\
2 & Very Low & Low \\
1 & & Very Low \\
\hline
\end{tabular}

\section{Research Subjects and Objects}

In this study, the sources or informants who were interviewed as research subjects were officials who were directly related to the development of the Islamic State Threat (IS). These sources are classified as expert people, among others:

Table 6

The Expert in this Research.

\begin{tabular}{clcc}
\hline \multicolumn{1}{l}{ Expert } & Kode & \\
\hline No & & Total & \\
\hline 1 & Ambassador / Defense Attache Thailand, Malaysia, and Philipines & E1-E3 & \\
2 & Ambassador / Defense Attache Pertahanan Indonesia for Thailand, Malaysia, and Philipines & E4-E6 & 3 \\
\hline
\end{tabular}


In this study, the object of research is the Islamic State (IS) terrorism network that is developing in Southeast Asia with case studies of 4 (four) major countries, namely Indonesia, Malaysia, Thailand, the Philippines.

\section{Result}

The risks to be faced in terms of national security in each country of course vary according to existing geopolitical conditions. In this connection, risk management is needed to see the risks faced and the effect of these risks on the objectives of the activity. Furthermore, solutions can be planned to minimize the impact of these risks so that they can support the realization of activity objectives. The most important step in risk management is identifying the risk. In this study, the Borda method and the dimensions of terrorism were used to identify and give weight to the risk criteria, while TOPSIS was used to determine the dominant risk in national security against the threat of IS in each country. This risk identification stage results in, among other things, a list of risks, which is a component of the overall risk management plan. In this study, the risk category consisted of Threat Aspects and Vulnerability Aspects. The threat aspect consists of 8 (eight) criteria while the Vulnerability aspect consists of 5 (five) criteria.

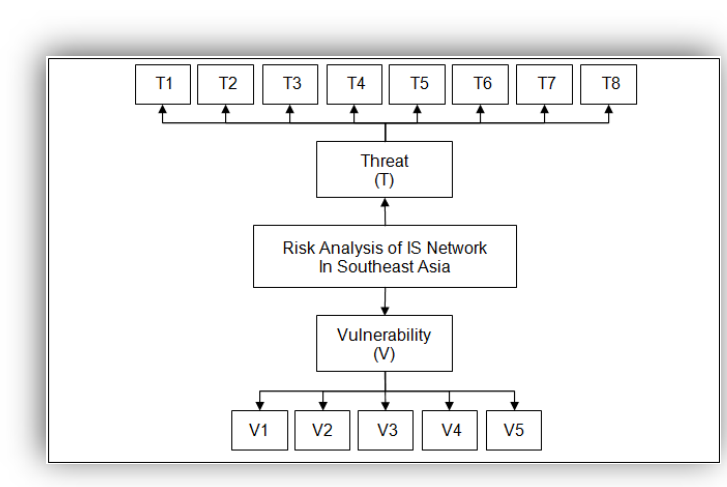

Fig. 1. Risk Analysis Structure of Islamic State Network

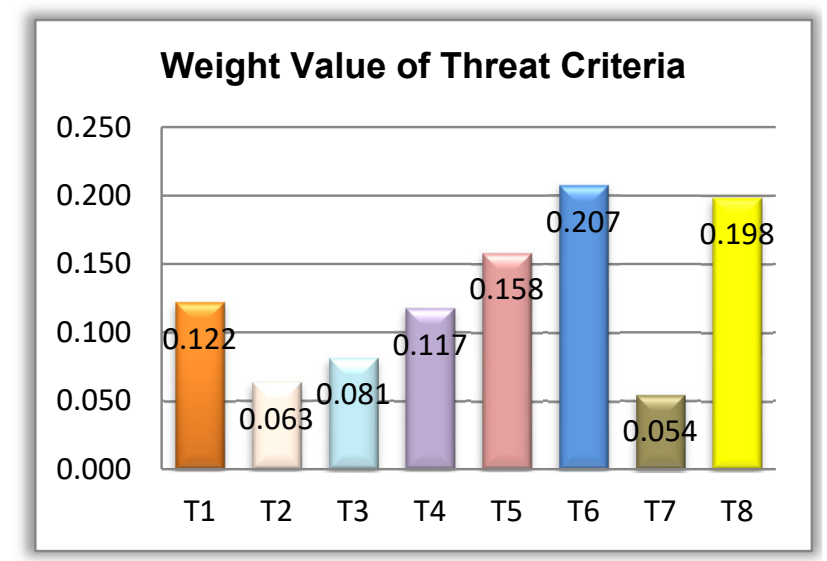

Fig. 2. Graphical Analysis of Threat Criteria value

The next step is followed by the process of weighting the criteria using the Borda method. After the qualitative and quantitative data for each alternative can be described, the next step is to assess the related criteria. In the data processing process for calculating the criteria weights with the Borda method using Microsoft Excels software and for alternative ranking processing using Microsoft Excels software.

\subsection{Weight Value of Threat Criteria}

Table 7

Expert Opinion and Weighted Value of Threat Criteria.

\begin{tabular}{|c|c|c|c|c|c|c|c|c|c|}
\hline \multirow{2}{*}{ Threat } & \multirow{2}{*}{ Code } & \multicolumn{6}{|c|}{ Expert } & \multirow{2}{*}{ Weight } & \multirow{2}{*}{ Rank } \\
\hline & & $\mathbf{I}$ & II & III & IV & $\mathbf{V}$ & VI & & \\
\hline Existence & T1 & 5 & 5 & 6 & 7 & 5 & 5 & 0.122 & 4 \\
\hline Enemy Terror Ability & $\mathrm{T} 2$ & 7 & 7 & 8 & 5 & 7 & 6 & 0.063 & 7 \\
\hline Historical & T3 & 6 & 8 & 4 & 6 & 4 & 8 & 0.081 & 6 \\
\hline Intensity & $\mathrm{T} 4$ & 4 & 6 & 5 & 3 & 6 & 4 & 0.117 & 5 \\
\hline Type of planning activities & T5 & 3 & 3 & 3 & 4 & 3 & 3 & 0.158 & 3 \\
\hline Strategic target & T6 & 1 & 2 & 1 & 1 & 2 & 1 & 0.207 & 1 \\
\hline Total Population & $\mathrm{T} 7$ & 8 & 4 & 7 & 8 & 8 & 7 & 0.054 & 8 \\
\hline Environmental Safety & $\mathrm{T} 8$ & 2 & 1 & 2 & 2 & 1 & 2 & 0.198 & 2 \\
\hline
\end{tabular}

Based on the results of the analysis calculations in Table 7 and Fig. 2, The strategic target sub-criteria have the highest value in the threat of terrorism activities with a weighting value of 0.207 . This is because every action that is carried out has a strategic target that is carried out. The lowest sub-criteria factor is the total population with a weight of 0.054 .

\subsection{Weight Value of Vulnerability Criteria}

Table 8

Expert Opinion and Weighted Value of Vulnerability Criteria.

\begin{tabular}{|c|c|c|c|c|c|c|c|c|c|}
\hline \multirow{2}{*}{ Vulnerability } & \multirow{2}{*}{ Code } & \multicolumn{6}{|c|}{ Expert } & \multirow{2}{*}{ Weight } & \multirow{2}{*}{ Rank } \\
\hline & & $\mathbf{I}$ & II & III & IV & $\mathbf{V}$ & VI & & \\
\hline Location & V1 & 1 & 5 & 1 & 1 & 5 & 5 & 0.214 & 2 \\
\hline Accessibility & V2 & 4 & 3 & 3 & 2 & 4 & 2 & 0.167 & 5 \\
\hline Adequacy of Security & V3 & 2 & 2 & 2 & 5 & 2 & 1 & 0.226 & 1 \\
\hline Availability & V4 & 5 & 1 & 5 & 3 & 1 & 4 & 0.202 & 3 \\
\hline
\end{tabular}


Based on the results of analysis calculations in Table 8 and Fig. 3, the Adequacy of Security sub-criteria has the highest value in the vulnerability aspect of terrorism activities with a weighting value of 0.226 . Adequacy of security is an important aspect of implementing terrorism activities. The more vulnerable the security of a country, the greater the opportunity for acts of terrorism. The lowest sub-criteria factor is accessibility with a weight of 0.167 .

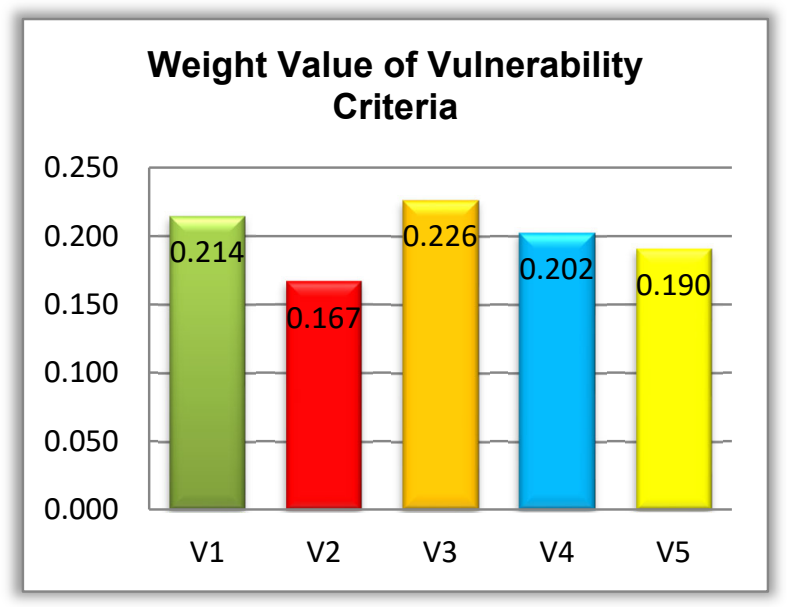

Fig. 3. Graphical Analysis of Vulnerability Criteria

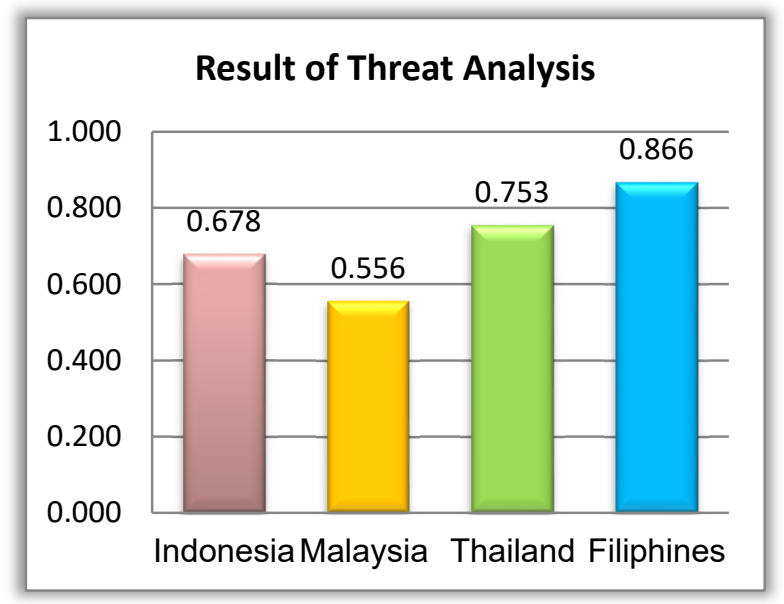

Fig. 4. Graph of Threat Aspect for Risk Analysis Score (T)

\subsection{Assessment of Threats and Vulnerability}

In determining the risk value of the Islamic State terrorism network (IS) using the TOPSIS method, we first calculate the weight for each of the criteria and alternatives. In calculating the TOPSIS, the criteria for Threat and Vulnerability are associated with countries in ASEAN, namely Indonesia, Malaysia, Thailand, and the Philippines. The integration process is used to determine risk analysis in the four existing countries. the first step is to identify the value of the threat (Threat) and the vulnerability (Vulnerability) then multiply the second. The value of the two is then identified in the risk matrix to determine the level of risk that exists today. Based on Table 10 and Fig. 4, TOPSIS calculation of the threat value can be seen that Indonesia has a threat value of 0.678 . Malaysia has a threat value of 0.556 . Thailand has a threat value of 0.753 . The Philippines has a threat value of 0.866 . Based on the results of this analysis, it is known that the Philippines has the highest threat value and Malaysia has the lowest threat value to the development of Islamic State (IS) in Southeast Asia.

Table 9

Calculation of the risk analysis matrix for the Threat aspects (T)

\begin{tabular}{|c|c|c|c|c|c|c|c|c|}
\hline \multicolumn{9}{|c|}{ Threat } \\
\hline Weight & 0,122 & 0,063 & 0,081 & 0,117 & 0,158 & 0,207 & 0,054 & 0,198 \\
\hline Alternative / Criteria & T1 & T2 & T3 & T4 & T5 & T6 & T7 & T8 \\
\hline Indonesia & 2 & 2 & 2 & 2 & 2 & 2 & 2 & 2 \\
\hline Malaysia & 2 & 2 & 2 & 1 & 2 & 1 & 1 & 2 \\
\hline Thailand & 3 & 2 & 3 & 2 & 2 & 2 & 3 & 3 \\
\hline Filiphines & 3 & 3 & 4 & 3 & 3 & 3 & 3 & 3 \\
\hline
\end{tabular}

Table 10

Value of Risk Analysis for Threat Aspects (T)

\begin{tabular}{|c|c|c|c|}
\hline \multicolumn{4}{|c|}{ Value of Threat } \\
\hline Alternative & D+ & D- & Result \\
\hline Indonesia & 0.078 & 0.164 & 0.678 \\
\hline Malaysia & 0.118 & 0.147 & 0.556 \\
\hline Thailand & 0.065 & 0.199 & 0.753 \\
\hline Filiphines & 0.038 & 0.247 & 0.866 \\
\hline
\end{tabular}

Table 11

Calculation of the risk analysis matrix for the Vulnerability Aspects (V)

\begin{tabular}{cccccc}
\hline & \multicolumn{3}{c}{ Vulnerability } & 0.226 & 0.190 \\
\hline Weight & 0.214 & 0.167 & $\mathbf{C 3}$ & $\mathbf{C}$ & \\
\hline Alternative / Criteria & $\mathbf{C 1}$ & $\mathbf{C 2}$ & 2 & 3 \\
Indonesia & 2 & 3 & 2 & 2 \\
Malaysia & 2 & 2 & 3 & 2 \\
Thailand & 3 & 3 & 3 & 3 \\
\hline
\end{tabular}




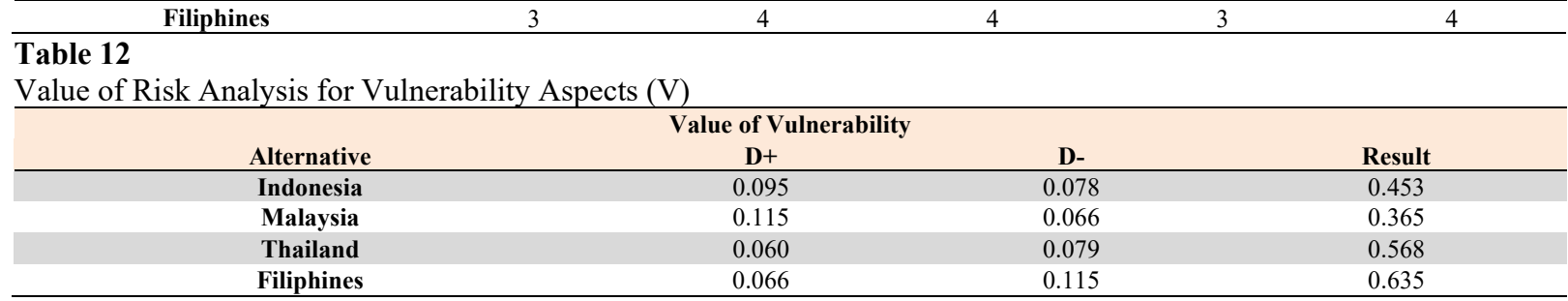

Based on Table 12 and Fig. 5, TOPSIS calculation of the Vulnerability value can be seen that the Indonesian state has a value of 0.453 . Malaysia has a Vulnerability value of 0.365 . Thailand has a Vulnerability value of 0.568 . The Philippines has a Vulnerability value of 0.635 . Based on the results of this analysis, it is known that the Philippines has the highest Vulnerability value and Malaysia has the lowest Vulnerability value towards the development of Islamic State (IS) in Southeast Asia.

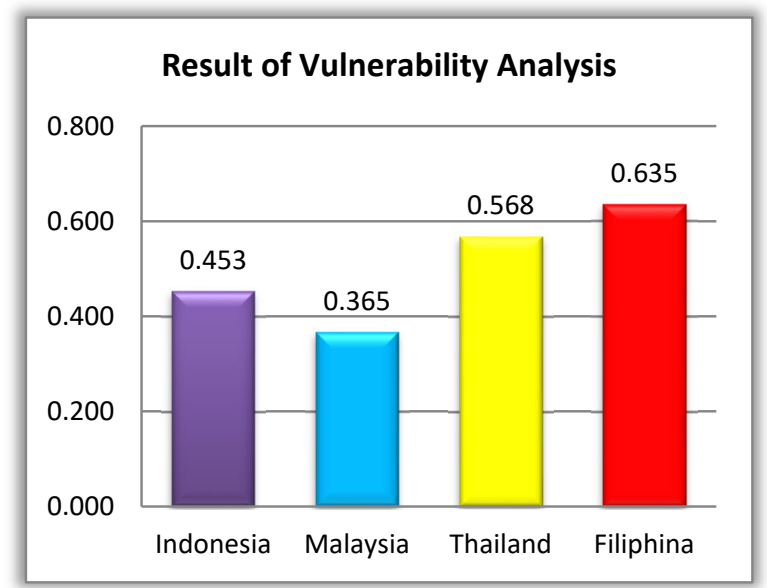

Fig. 5. Graph of Vulnerability Aspect for Risk Analysis Score $(\mathrm{T})$

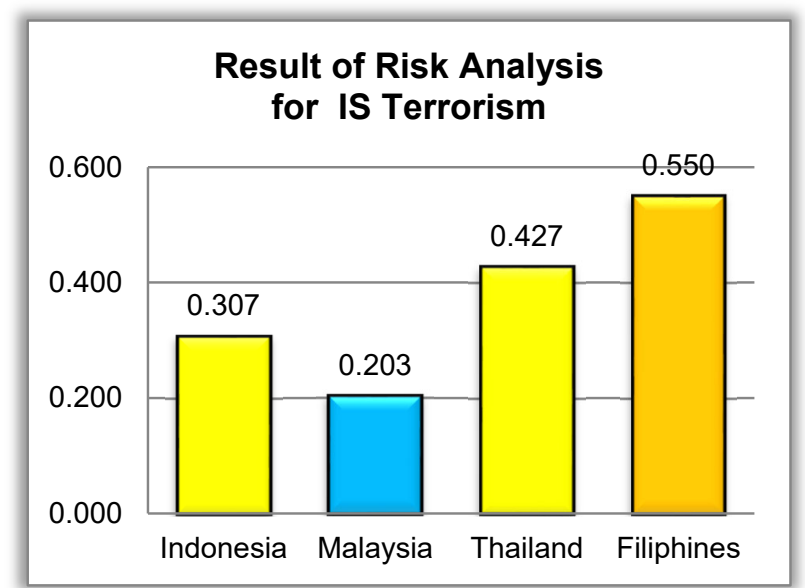

Fig. 6. Graphic of Risk Value to Islamic State (IS) Network in Southeast Asia

\subsection{Determination of Risk Value}

The analysis results explain that several conditions stand out and at each stage of construction. The risks to be faced in terms of national security in each country of course vary according to existing geopolitical conditions.

Table 13

Risk Value toward the Islamic State (IS) Network in Southeast Asia

\begin{tabular}{|c|c|c|c|c|c|}
\hline Country & Threat Score & Vulnerability Score & Risk Score & Alert Level & Colour \\
\hline Indonesia & 0,678 & 0,453 & 0,307 & Medium & Level 3 \\
\hline Malaysia & 0,556 & 0,365 & 0,203 & Low & Level 2 \\
\hline Thailand & 0,753 & 0,568 & 0,427 & Medium & Level 3 \\
\hline Filiphines & 0,866 & 0,635 & 0,550 & High & Level 4 \\
\hline
\end{tabular}

Based on Table 13 and Fig. 6, the risk value derived from the multiplication of the Threat value (T) and Vulnerability (V). Based on the results of the risk calculation analysis, it was found that the Philippines has the highest risk factor value for Islamic State (IS) with a value of 0.550 at level 4 in the High category. Indonesia has a risk factor value of 0.307 . Thailand has a risk factor value of 0.427 . Indonesia and Thailand are at level 3 with the Medium category. Meanwhile, Malaysia has a risk factor value of 0.203 at level 2 in the Low category.

\section{Conclusion}

The Islamic State (IS) terrorism network in Southeast Asia cannot be separated from the spread of power from the Islamic State group in Iraq and Syria. The presence of combatants from various countries has a risk impact on the development of the Islamic State (IS) group, especially combatants from Southeast Asia. Based on the results of the risk analysis regarding the development of the Islamic State (IS) network, it is found that the risk analysis of the threat criteria is that Indonesia has a threat value of 0.481 . Malaysia has a threat value of 0.289 . Thailand has a threat value of 0.470 . The Philippines has a threat value of 0.736 . Based on the results of the risk analysis of the vulnerability criteria, it was found that Indonesia had a Vulnerability value of 0.471 . Malaysia has a Vulnerability value of 0.181 . Thailand has a Vulnerability value of 0.452 . The Philippines has a Vulnerability value of 0.847 . Based on the results of the overall risk analysis, it was found that the 
Philippines has the highest risk factor value for Islamic State (IS) with a value of 0.550 at level 4 in the High category. Indonesia has a risk factor value of 0.307 . Thailand has a risk factor value of 0.427 . Indonesia and Thailand are at level 3 with the Medium category. Meanwhile, Malaysia has a risk factor value of 0.203 at level 2 in the Low category.

\section{Future Work}

In further research, a mitigation strategy can be carried out against the risk factors for the Islamic State (IS) terrorism network in Southeast Asia by carrying out cooperation in the field of security and counterterrorism.

- In further research, risk mitigation analysis can be given to other Southeast Asian countries to identify as a whole about the development of the Islamic State (IS).

\section{References}

Alencar, L. H., Almeida, A. T. d. \& Morais, D. C. (2010). A multicriteria group decision model aggregating the preferences of decision-makers based on Electre methods. Pesquisa Operaciona, 30(3), 687-702.

Brito, M. M. d. \& Evers, M. (2016). Multi-criteria decision-making for flood risk management: a survey of the current state of the art. Natural Hazard and Earth System Sciences, 16, 1019-1033.

Chen, H. M. W., Chou, S.-Y., Luu, Q. D. \& Yu, T. H.-K. (2016). A fuzzy MCDM approach for green supplier selection from the economic and environmental aspects. Mathematical Problems in Engineering, 1-10.

Chien, L.-K., Wu, J.-P. \& Tseng, W.-C. (2019). The study of risk assessment of soil liquefaction on land development and utilization by GIS in Taiwan. Dalam: Geographic Information Systems, s.l.(Intechopen), 1-19.

Cioaca, C., Constantinescu, C.-G., Boscoianu, M. \& Lile, R. (2016). Extreme risk assessment methodology (ERAM) in aviation system. Environmental Engineering and Management Journal, 14(6), 1399-1408.

Dadras, M., Shafri, H. Z. M., Ahmad, N., Pradhan, B., \& Safarpour, S. (2014). A combined FUZZY MCDM approach for identifying the suitable lands for urban development: an example from Bandar Abbas, Iran. Journal of Urban and Environmental Engineering, 8(1), 11-27.

Dumbravă, V. \& Iacob, V. -. S. (2013). Using probability-impact matrix in analysis and risk assessment projects. Journal of Knowledge Management, Economics and Information Technology, pp. 76-96.

Ezell, B. C., Bennett, S. P., Von Winterfeldt, D., Sokolowski, J., \& Collins, A. J. (2010). Probabilistic risk analysis and terrorism risk. Risk Analysis: An International Journal, 30(4), 575-589.

Khairunnisa, K., Farmadi, A., \& Kartika, H. C. (2016). Penerapan Metode Ahp Topsis Pada Sistem Pendukung Keputusan Penentuan Taman Kanak-Kanak (TK) Terbaik Dari Dinas Pendidikan Kota Banjarbaru (Studi Kasus TK di Kecamatan Banjarbaru Selatan). Klik-Kumpulan Jurnal Ilmu Komputer, 2(1), 1-10..

Fuentes-Bargue, J. L., González-Cruz, C., C. G.-G. \& Baixauli-Pérez, P. (2017). Risk analysis of a fuel storage terminal using HAZOP and FTA. International Journal of Environment Research and Public Health, 14(705), 1-26.

Ganin, A. A., Quach, P., Panwar, M., Collier, Z. A., Keisler, J. M., Marchese, D., \& Linkov, I. (2020). Multicriteria decision framework for cybersecurity risk assessment and management. Risk Analysis, 40(1), 183-199.

Gavade, R. K. (2014). Multi-Criteria Decision Making: An overview of different selection problems and methods. International Journal of Computer Science and Information Technologies, 5(4), 5643-5646.

Gebrehiwet, T. \& Luo, H. (2019). Risk level evaluation on construction project lifecycle using fuzzy comprehensive evaluation and TOPSIS. Symmetry, 11(12), 1-15.

Hashim, A. S. (2015). The Impact of the Islamic State in Asia, Singapore: Institute of Defence and Strategic Studies (IDSS).

Hosseinnia, B., Khakzad, N. \& Reniers, G. (2018). An emergency response decision matrix againts terrorist attack with improvised device in chemical cluster. International Journal of Safety and Security Engineering, 8(2), 187-199.

Kaewunruen, S., Alawad, H. \& Cotruta, S. (2018). A decision framework for managing the risk of terrorist threats at rail stations interconnected with Airports. Safety, 36(4), 1-19.

Kripalani, R. \& Kulkarni, A. (1997). Rainfall variability over south-east Asia-connections with Indian monsoon and enso extremes: New perspective. International Journal of Climatology, 17, 1155-1168.

Liua, C., Tan, C.-K., Fang, Y.-S. \& Lok, T.-S. (2012). The security risk assessment methodology. International Symposium on Safety Science and Engineering in China, p. $600-609$.

Logan, C. \& Lloyd, M. (2019). Violent extremism: A comparison of approaches to assessing and managing risk. Legal and Criminological Psychology, 24, 141-161.

Loo, Y. Y., Billa, L. \& Singh, A. (2015). Effect of climate change on seasonal monsoon in Asia and its impact on the variability of monsoon rainfall in Southeast Asia. Geoscience Frontiers, 6, 817-823.

Merlin, V., 2020. The axiomatic characterizations of majority voting and scoring rules. Mathématiques et sciences humaines, 41(161), 87-109.

Nainggolan, P. P. (2017). Kekhalifahan ISIS di Asia Tenggara, Sekedar Wacana atau Realitas ?. Politica, 8(2), $205-230$.

Norouzi, A. \& Namin, H. G. (2019). A hybrid fuzzy TOPSIS - best worst method for risk prioritization in Megaprojects. Civil Engineering Journal, 5(6), 1257-1272.

Pavlićević, P. (2017). Rationality of terrorist acts, counterterrorism and risk analysis. Law and Politics, 15(4), $291-304$.

Rađenović, Ž., \& Veselinović, I. (2017). Integrated AHP-TOPSIS method for the assessment of health management information systems efficiency. Economic Themes, 55(1), 121-142. 
Sadeh, N. \& Rezaian, S. (2017). Risk management and control of dams based on integrating TOPSIS and RAM-D techniques (Case Study: Paveh Rood Dam, Iran). Environmental Energy and Economic Research, 1(4), $363-372$.

Samuel, T. K. (2016). Radicalisation in Southeast Asia: A selected case study of Daesh in Indonesia, Malaysia and the Philippines. 1st penyunt. Kuala Lumpur: The Southeast Asia Regional Centre for Counter-Terrorism (SEARCCT),.

Sari, R. P., Istikoma \& Supriadi, F. (2020). The Comparison of SAW BORDA and TOPSIS BORDA Methods In the Zakat Recipient Determination System Education programs (Case Study: BAZNAS, West Kalimantan Province). WMA.

Sarma, K. M. (2017). Risk assessment and the prevention of radicalization from nonviolence into terrorism. American Psychologist, 72(3), 278-288.

Srdjevic, B., Srdjevic, Z. \& Medeiros, Y. D. P. (2017). Multicriteria and Social Choice Methods in Assessing Water Management Plans. Chania, HAICTA .

Suharyo, O. S., Manfaat, D. \& Armono, H. D. (2017). Establishing the location of naval base using fuzzy MCDM and covering technique methods: A Case Study. International Journal of Quantitative Management, 23(1).

Wan, C., Yan, X., Zhang, D. \& Shi, J. (2014). Facilitating AHP-TOPSIS Method for Reliability Analysis of a Marine LNGDiesel Dual Fuel Engine, s.1.: s.n.

Wang, C.-N., Huang, Y.-F., Cheng, I.-F. \& Nguyen, V. T. (2018). A multi-criteria decision-making (MCDM) approach using hybrid SCOR metrics, AHP, and TOPSIS for supplier evaluation and selection in the Gas and Oil Industry. Processes, 6(252), 1-12.

Wang, S., Wang, G. \& Zhang, J. (2019). Data analysis method of terrorist attacks based on AHP-DBSCAN method. Journal of Physics, 1168, 1-8.

Wang, X. \& Duan, Q. (2019). Improved AHP-TOPSIS model for the comprehensive risk evaluation of oil and gas pipelines. Petroleum Science, 16, 1479-1492.

Woo, G. (2009). Terrorism threat assessment and management. Defence Against Terrorism Review, 2(1), 101-116.

Yang, J. (2019). Risk Evaluation Of Terrorist Attacks Against Important Chemical Industries In Urban Areas. Wuhan, Atlantic Press, pp. 1-4.

Zawadzki, M., Costa, A. N., Belderrain, M. C. N., \& Montibeller, G. (2017). Adversarial risk analysis in support of defensive resource allocation for counterterrorism. Gestão \& Produção, 24(3), 450-463.

Zhang, X., Jin, M., Fu, J., Hao, M., Yu, C., \& Xie, X. (2018). On the risk assessment of terrorist attacks coupled with multisource factors. ISPRS International Journal of Geo-Information, 7(9), 354.

Zierhoffer, D. M. (2014). Threat assessment: Do lone terrorists differ from other lone offenders?. Journal of Strategic Security, 7(3), 48-62.

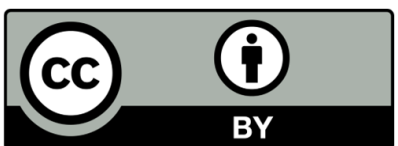

(C) 2021 by the authors; licensee Growing Science, Canada. This is an open access article distributed under the terms and conditions of the Creative Commons Attribution (CC-BY) license (http://creativecommons.org/licenses/by/4.0/). 